\title{
Faculty Redefined
}

\author{
Libby V. Morris
}

Published online: 20 June 2009

(C) Springer Science + Business Media, LLC 2009

All across the United States, the headlines tell stories of bankruptcies, layoffs, foreclosures, declining state revenues, and other economic woes. Colleges and universities share in the suffering as state appropriations to public institutions decline, as endowments shrink, and as the expenses of running a college or university continue to climb. Even the highly selective, private institutions are caught in the current economic crunch.

A fairly common response is emerging: raise college tuition, make the consumer pay more. Yet, how feasible is this approach in the short-term and long-term? How much can a potential student pay, especially if the family or student is now underemployed, unemployed, or in bankruptcy? Indeed laid-off workers may have time on their hands for studying in college, but they may have no money in the bank and no interest in taking on more loans. Thus, higher tuition may be an empty solution.

Another approach to balancing the budget is to control costs and roll back expenditures. Institutions near and far are reducing budgets by $8 \%, 10 \%$ and $12 \%$, if not more, and are sometimes writing furloughs into the contracts of tenured faculty. Even when the economy improves, higher education may not be the first to restore its losses and recoup its longstanding high priority, as other social and political concerns take the stage to compete for public dollars.

The economic woes of higher education are not new. The transformation of our institutions from a predominantly tenured faculty to including a much larger proportion of contingent instructors has been building for more than a decade. The long-term impact of this "cost-saving" measure is largely unrecognized by the general public and many within the academy. The recently released report entitled The State of the Higher Education Workforce, 1997-2007 by the American Federation of Teachers reveals the sharp decline in the proportion of tenured faculty and tenure-track positions and the increasing use of fulltime and part-time adjuncts and graduate students for instruction. In 2007, contingent faculty members held almost three-quarters of the instructional positions in colleges and universities across the United States, up from two-thirds a decade earlier; and, according to the report, tenured and tenure-track faculty members were not in the majority in any sector! In 2007, part-time instructors made up almost $69 \%$ of the instructional staff in community colleges; and in public research universities less than one-third (29\%) of faculty were full-

L. V. Morris $(\bowtie)$

Institute of Higher Education, University of Georgia, 102 Meigs Hall, Athens, GA 30602-6772, USA

e-mail: lvmorris@uga.edu 
time tenured or on tenure track; $14 \%$ were full-time non-tenure track, $16 \%$ part-time faculty, and $41 \%$ graduate assistants. This entire report may be viewed at http://www.aftface.org/ storage/face/documents/ameracad_report_97-07for_web.pdf.

The changes in the academic workforce may have multiple impacts, both individual and institutional. First, each year a large number of new Ph.D. graduates face the difficult task of finding a full-time position, much less a tenure track position. The teaching positions held as a graduate student are the entry level positions they cannot access as new graduates. This cost-saving measure of using graduate student teachers and part-time instructors may eventually erode the specialized programs that they are now designed to protect. At what point will the negative impact of over-supply and under-demand (by the institutions who created them!) for Ph.D.s in academic positions begin to have a negative impact on high quality applicants for the long and difficult task of the Ph.D. degree? In public comprehensive institutions, $6 \%$ of the instructional staff members were graduate students; and $44 \%$ were part-time faculty. I wonder if the doctoral students noticed and believed it could happen to them.

Clearly the data show that many doctoral graduates finally settle, at least in the early years following graduation, for part-time and adjunct positions, perhaps in multiple places. For some part-time instruction is a voluntary state. Their personal interest has matched with an institutional need, and a long-term relationship may ensue.

Why should we be concerned that the instructional mission across colleges and universities is carried out by a contingent labor force? We should not assume that adjuncts or part-time faculty are disinterested in the institution or in students or that they are poor instructors. In fact, most are eager to teach. Yet, looking beyond the staffing patterns and career conditions in higher education, which is a primary concern of the American Federation of Teachers, the changing academic workforce may profoundly affect other individuals, especially undergraduate students. Undergraduates in both selective and nonselective institutions with higher numbers of contingent faculty are increasingly less likely to have courses with faculty members who will return from year to year, who are available as mentors and are engaged in the life of the department and discipline, and who are immersed in the culture of the institution and participate in the debates about the curriculum. Part-time faculty members will be far less likely to engage in institution-wide goal-setting for learning, assessment of student outcomes, selecting a cohort of students for admission, and presiding over the academic affairs of the institution. They may wish to do so, but models for doing so are likely in a nascent stage.

This situation brings me to my final point and question: the trends are clear that the growth in contingent faculty will continue and that the proportion of tenured and tenuretrack faculty will decline. Accordingly, what can we do in instructional and organizational development, that is innovative, to address the needs and priorities of the individual and institution in this growing population? Just as I began writing about this trend, I came across an article by Laursen and Rocque in the March/April 2009 issue of Change, titled "Supporting Faculty, Transforming Institutions." As a small part of a larger project on "institutional transformation" to increase the numbers of women in science, technology, engineering, and mathematics (STEM), the researchers interviewed 44 tenure track faculty at a research university and developed three tiers of faculty needs-individual, organizational, and systemic. I was struck by the likely areas of overlap and disconnect between the permanent faculty and the large contingent "core." What are the tiers for the new majority? How will we redefine "faculty development" for the not-so-permanent faculty? What does institutional transformation mean in light of faculty redefined? These remain some of our unanswered questions. 